Sharif University of Technology
Scientia Iranica
SCIENTIA
I RAN I CA
Transactions A: Civil Engineering
www.scientiairanica.com

\title{
Predicting labor costs in construction projects using agent-based modeling and simulation
}

\author{
Sh. Dabirian ${ }^{\mathrm{a}}$, M. Khanzadi ${ }^{\mathrm{a}, *}$ and M. Moussazadeh ${ }^{\mathrm{b}}$ \\ a. School of Civil Engineering, Iran University of Science and Technology, Tehran, Iran. \\ b. School of Civil Engineering, Islamic Azad University, Arak Science \& Research Branch, Arak, Iran. \\ Received 5 July 2014; received in revised form 22 November 2014; accepted 16 January 2016
}

\author{
KEYWORDS \\ Agent-based \\ modeling; \\ Simulation; \\ Construction; \\ Labor costs; \\ AnyLogic.
}

\begin{abstract}
In most construction projects, human resources account for 30 to 50 percent of all project costs, thus it is an important cost element in construction projects. However, the complexities and uncertainty of work flow have made it difficult to predict human resource costs. The most effective and economic management approach is computer simulation which has a better ability to understand and identify the dynamics and statics of a case research system. One of the steps of simulation is modeling, and choosing the best modeling approach for prediction is very important. Agent-based modeling, which is referred to by some as "a third way of doing science", was chosen to predict labor cost impacted by many factors in the work flow. In our research, the increased labor cost, based on factors affecting work flow, is 16 percent on average, which is predicted more accurately by the simulated model than by planned cost.

(C) 2016 Sharif University of Technology. All rights reserved.
\end{abstract}

\section{Introduction}

There is no doubt that construction is a key element in the economic activities of a country [1]. Human resource costs account for 30 to 50 percent of all construction project costs [2]. Thus, human resources are a valuable asset to every construction project and an important resource in reaching economic growth. Understanding the impact level of factors on labor cost, which has a greater chance to lower costs in effective management compared with other cost management components, is critical.

Construction projects are becoming complex in an unprecedented way because of growing uncertainties in cost estimating processes [3]. Construction researchers have applied different approaches to study the com-

\footnotetext{
*. Corresponding author. Mobile: +98 912 3121025; Fax: +9821 ry240398

E-mail addresses: dabirian@iust.ac.ir (Sh. Dabirian);

khanzadi@iust.ac.ir (M. Khanzadi);

moussazadeh.mehdi@gmail.com (M. Moussazadeh)
}

plexities and improve cost management, including the critical path method, the PERT probabilistic network, Queuing theory, and cost performance control models. They also mention tools such as game theory, simulation and linear programming in operational research. The advent of simulation methods in construction occurred in the form of the introduction of simple networking concepts, as a modeling framework for studying construction operations [4]. The earliest of these methods was the so-called "link node" model adapted by Teicholz (1963) [5].

The most effective and economic management approach is computer simulation which has better ability to understand and identify the dynamics and statics of case research systems [6]. Computer simulation is developing in parallel with computer technological advancement. Therefore, it has become a widely accepted method among researchers in operational research [7]. Halpin (1973) [8] developed the CYCLONE format at the University of Illinois, which has become the basis for a number of construction simulation systems. CYCLONE simplified the sim- 
ulation modeling process and made it accessible to construction practitioners with a limited simulation background. A microcomputer version of CYCLONE was developed by Liuch and Halpin (1981) at Georgia Institute of Technology [9]. This version is called the MicroCYCLONE. Paulson (1987) [10] developed the INSIGHT system, which is based on CYCLONE methodology and has a more interactive interface. Touran (1981) [11] focused on automated real time data acquisition and its integration with INSIGHT. Work at the University of Michigan under supervision of Chang and Carr led to the development of RESQUE which is also CYCLONE-based with advanced resource handling capabilities [12]. Ioannou (1989) [13] developed the UM-CYCLONE for advanced construction process modeling [4].

Discrete event simulation has been widely used as a simulation approach for cost performance in construction industry literature. The current research has attempted to clarify applicable information about agent-based modeling. In addition, AnyLogic software has been introduced as a simulator and used to propose the model for predicting labor costs by simulating the work flow in a construction project. The major research question is how much the studied project labor costs have been affected by the factors affecting work flow.

\section{Costs in the construction industry}

The construction industry is more important in developing rather than developed countries, and absorbs a major part of capital turnover [14]. Millions of dollars are spent on infrastructures and construction projects in developing countries every year. Regarding the high demand for housing in Iran and moving towards the national development plan, large-scale building projects are being carried out and a great deal of money is being spent. For instance, the overall building credits being approved for the fourth economic, social and cultural development plan of Iran is 701.3 trillion Rials for national building programs, and 198.8 trillion Rials for provincial programs.

There is no doubt that the construction industry is a key component of a country's economic activities [1]. Construction projects are almost labor intensive and labor costs account for 30 to 50 percent of total project costs [2]. Thus, workers are valuable assets to every country and known as important resources in leading the country to economic growth and set goals. Since the labor costs are so high, controlling them is a key function for higher profitability in the construction industry. Labor costs are also the least reliable factors among all cost components, such as materials, equipment and human resources. Materials and equipment are almost always based on the market price and are out of the project management control [15]. Therefore, realizing the effect of factors on labor costs is vital compared to other cost components, as it has a greater chance to lower costs through efficient management.

The construction industry has always encountered problems, usually related to labor performance. $\mathrm{Nu}$ merous factors, which are directly related to cost, time and quality performance, affect labor performance [16] Labor cost performance estimation is a vital tool for successful termination of the construction process. Moreover, in developing countries, construction sites have high risks originating from the effect of objective cost factors, so, construction practitioners need efficient tools to help them estimate costs more accurately. Simulation models used for construction processes are effective management tools for cost estimation [17]. For projects with manageable sizes to be simulated, computer simulation is a logical and practical tool for studying the quantitative effect of variable factors on activity costs. Computer simulations, particularly the ones based on modeling, have been developing for years, and some of them have been mentioned by Halpin in 1990 [18].

\section{Agent-based modeling}

Simulation is the process of designing the dynamic model of an actual dynamic system for the purpose of either understanding the behavior of the system or evaluating various strategies (within the limits imposed by a criterion or a set of criteria) for operation of the system [19]. Simulation is classified into continuous or discrete categories. In discrete simulation, the state of the system changes discretely only at occurred events with either a discrete or continuous time change. In a continuous simulation model, the state of the system is represented by dependent variables which change continuously over time with either a discrete or continuous time change. For simplicity, most work in construction simulation falls into the discrete sector. Simulation is the technology of experimenting on a computer with a mathematical and/or logical model built for a real world system that involves three phases: modeling, experimentation, and optimization [20].

One approach for solving real world problems is modeling, including the mapping of real world problems in modeling systems [21]. Agent-Based Modeling and Simulation (ABMS) includes a relatively new approach to modeling complex systems composed of interacting, autonomous 'agents' [4]. Agents have behaviors, often described by simple rules, and interactions with other agents, which, in turn, influence their behavior [22]. By modeling agents individually, the full effects of the diversity that exists among agents in their attributes and behaviors can be observed as it gives rise to the behavior of the system as a 
whole. By modeling systems from the 'ground up' agent by agent and interaction-by-interaction - selforganization can often be observed in such models. Patterns, structures, and behaviors emerge that are not explicitly programmed into the models, but arise through agent interactions. The emphasis on modeling the heterogeneity of agents across a population and the emergence of self-organization are two distinguishing features of agent-based simulation, as compared to other simulation techniques such as discrete event simulation and system dynamics [22-24].

Agent-based modeling, which is referred to by some as "a third way of doing science", and is able to augment traditional deductive and inductive reasoning as a discovery method [25], has roots that some researchers have traced back as far as the 1940s. However, serious computerized agent-based modeling began with the Santa Fe Institute's introduction of SWARM language in the mid-1990s. It expanded somewhat with RePast, in the late 1990s, and became much more widespread with the introduction of NetLogo in the early 2000s [26]. ABMS can be tracked to explore complex systems [27], complex adaptive systems [28,29], and artificial life [30] known as 'A Life' (see [31]) for a review of the influences of investigations into artificial life on the development of agent-based modeling) consist of interacting, autonomous components; complex adaptive systems have the additional capability of agents being able to adapt at individual or population levels [22].

ABMS is a new modeling approach that has gained increased attention over the past decade. This growing trend is approved by the increasing number of articles appearing in modeling and application journals. There is no universal agreement in the literature on the precise definition of an agent [22], however, agents may share the following properties and attributes, as shown in Figure 1 [31]. A typical agentbased model has three elements:

1. A set of agents, their attributes and behaviors;

2. A set of agent relationships and methods of interaction: An underlying topology of connectedness defines how and with whom agents interact;

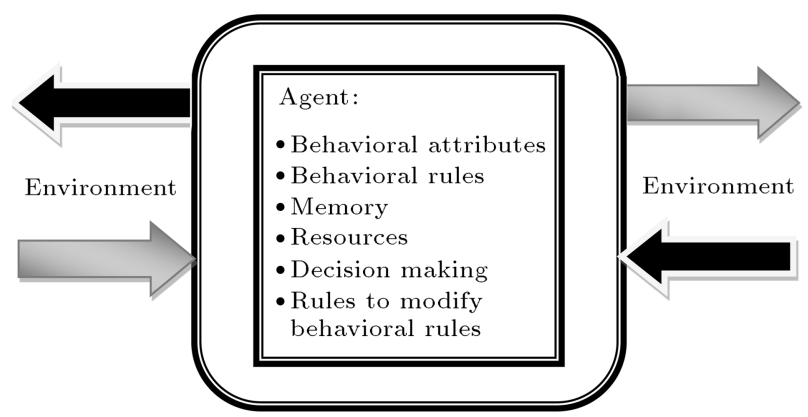

Figure 1. A typical agent attributes [31].
3. The agents' environment: Agents interact with their environment in addition to other agents [22].

\section{4. $\mathrm{ABM}$ in construction}

Construction discipline has always been of special concern to the public and also to researchers and practitioners who believe that there is a "central control" behind every construction project. Thus, once the plan is created, it is assumed that the project will evolve over this plan and that the interaction of construction "entities" will have a minimal impact on this evolution. Howell [32] recommended that the events in the field of the construction discipline could be described better based on an agent-based concept. As low-level data, on site activities seem to show more "organic" control compared to the much subscribed central and coordinated control $[32,33]$. Systems that show these kinds of behavior are amenable to the use of agent-based modeling and a simulation-based approach [4]. Agent-based modeling can be used to predict what happens in the real world. As traditional prediction approaches, such as discrete and continuous event simulation, are only able to model limited levels of abbreviation, they can only be used for prediction at limited levels. However, the agent-based approach can model and predict systems with different levels of abbreviation.

Construction projects are becoming complex in an unprecedented way because of growing uncertainties within various processes [34]. As an emerging computational simulation approach, ABM has been recognized as a suitable tool for capturing complexity. ABM reproduces a system by simulating the simultaneous actions of various autonomous individuals, or agents, in a system [25]. Unlike top-down modeling approaches (e.g. system dynamics and discrete event simulation), ABM provides insight into the fundamentals of a process and sometimes leads to counterintuitive conclusions. For example, Watkins et al. [35] used ABM to investigate the influence of a work arrangement strategy on construction productivity. They revealed that adding labor to a construction site does not always lead to a better outcome; instead, it may even reduce productivity, significantly, in some cases.

\section{AnyLogic}

The AnyLogic Company was founded in 1992. AnyLogic was first introduced at a Winter Simulation Conference in 2000. Almost all existing tools for simulation modelers are designed to support some particular modeling paradigm, but AnyLogic is the only simulation tool that supports Discrete Event, Agent Based, and System Dynamics Simulation, as shown in Figure 2 [21]. Historically, AnyLogic was 


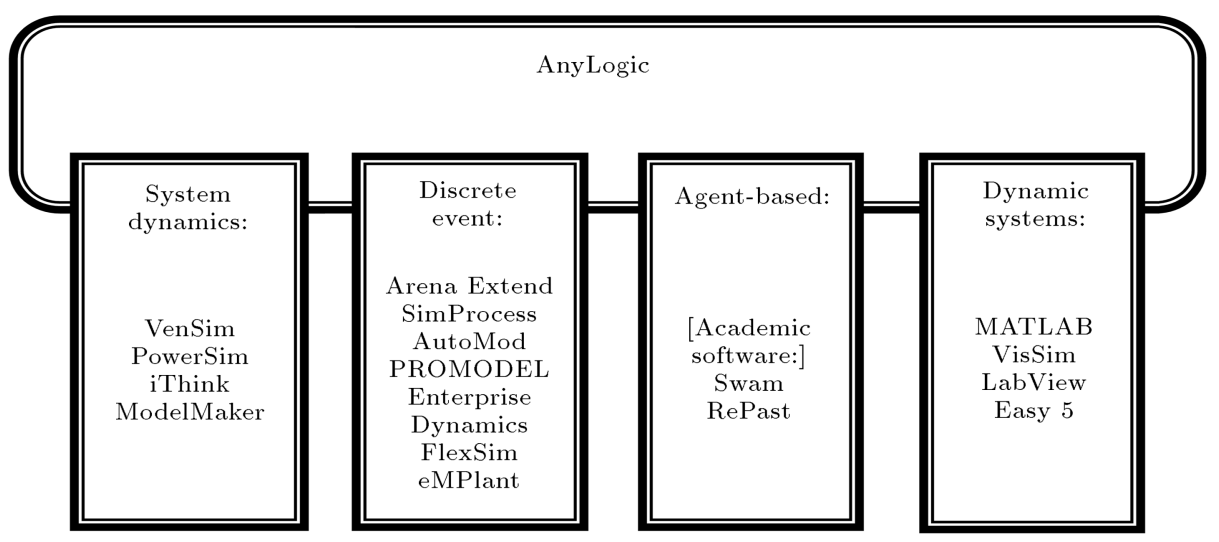

Figure 2. Tools for simulation modeling [21].

developed not by simulation modelers but by people with a background in distributed systems, concurrency theory and computer science. Therefore, none of the classical simulation modeling paradigms were used as a foundation. Instead, approaches and languages designed to handle complexity, and adopted in the software en gineering world, were implemented. AnyLogic's newest version, 6.9 , focuses mainly on the agent-based approach and 3D animation, but allows other methods to be used. In this modeling approach, agent behavior is defined as a state-chart, which is actually a state machine with several useful enhancements. Statecharts enable the user to graphically capture different states of agents, transition between them, events that trigger those transitions, timing, and actions that the agent makes during its life time. A clear advantage of AnyLogic is the possibility to use JAVA code at any place of the program, and thus, expand or adapt the model to the programmers needs $[24,36,37]$.

\section{Research methodology}

Cost estimation and prediction for performing activities have been undertaken in research by considering crew productivity and by simulating work flow in a construction site; agent-based modeling has been chosen for simulation as an applied approach. Later, the application of ABM for cost prediction of activities will be explained. To this end, a case study has been undertaken in the Tabriz world trade center project. Due to research limitations and the project phase (which has been in the finishing and plumbing/electrical phase), cost prediction has been done for activities including plastering, tiling, wiring and plumbing. The case study in the current research includes Tabriz world trade towers as part of a world trade centre project in Tabriz, Iran. They will be built in an area of $22000 \mathrm{~m}^{2}$ in Valiasr Street. The world trade centre towers are to be built in an area of $41000 \mathrm{~m}^{2}$. It must be mentioned that the number of workers had been increased in the project under study to compensate for the project being behind schedule. In order to achieve the goal of the research, the prediction model has been run based on the rules and assumptions considered in AnyLogic software introduced previously.

\subsection{Identifying the system in reality and determining the system boundaries}

In this research, a construction site has been chosen as the system under study. The system consists of components such as: activities, workers, the environment, and effective factors on the work procedure. The components interact with each other and create the work flow in the construction site based on simple rules. The research system has been shown in Figure 3. Adequate realization of how system components interact with each other and having a realistic outlook of conditions governing the project could enhance the validity of system outputs.

\subsection{System modeling using agents' state-charts and interaction rules}

Modeling using the ABM approach will be developed, based on what has been stated up to now. In order to better realize the work flow, the activities have been divided into specific tasks, so that the work process could be better perceived. For instance, total tiling activity is $900 \mathrm{~m}^{2}$ and has been divided into thirty six 25-square meter tasks, so that the work flow could

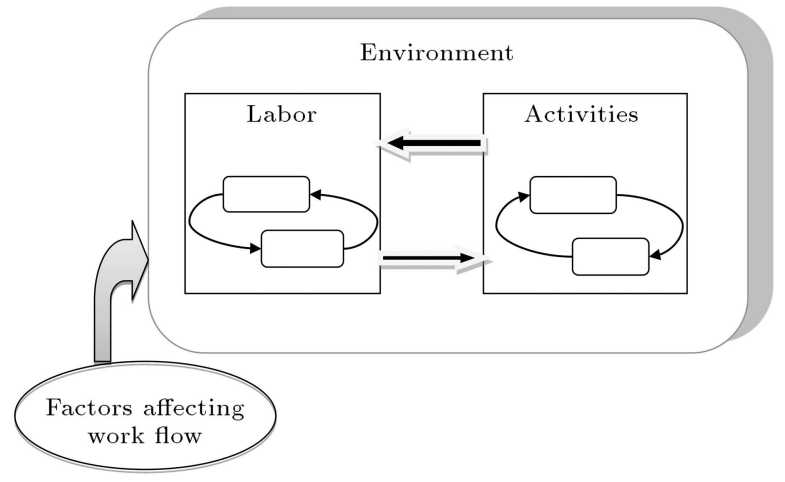

Figure 3. Context model of researched system. 
be better observed. Simulation has taken place in a continuous environment but with discrete changes.

Agent-based modeling has been defined, based on the following rules:

1) There are two kinds of agent in the model: Tasks $(T)$ and Worker $(W)$;

2) There are four groups of worker, including: Electrician, Plumber, Plasterer, and Tiler;

3) There are four kinds of task in the task agent, which include: Wiring, Plumbing, Plastering, and Tiling;

4) In each skill, there is a working crew of three;

5) In order to grasp the work flow, a determined skill level has been assigned to every worker. Skill level is based on data gathered from case study projects and has been allocated to laborers. Therefore, there is no need to use probabilistic distribution in the research model, being based on the real world. Project data related to skill level has been given in Table 1, which shows the average of multiple unit productions per hour for different times of work and labor. As stated, the current research is one of the first attempts in Iran and other countries; thus, using probabilistic distribution could be an

Table 1. Quantity of parameters used in the model.

\begin{tabular}{cccc}
\hline Unit & Value & Group & Title \\
\hline $\mathrm{m}$ & 50 & EWorker & \\
$\mathrm{m}^{2}$ & 12.5 & PWorker & Skill level \\
$\mathrm{m}^{2}$ & 1.25 & TWorker & \\
$\mathrm{m}$ & 6000 & EActivity & \\
$\mathrm{m}$ & 2550 & PActivity & Activity \\
$\mathrm{m}^{2}$ & 1500 & SActivity & \\
$\mathrm{m}^{2}$ & 900 & TActivity & \\
$\mathrm{m}$ & 400 & ETask & \\
$\mathrm{m}$ & 50 & PTask & Task \\
$\mathrm{m}^{2}$ & 50 & STask & \\
$\mathrm{m}^{2}$ & 25 & TTask & \\
$\mathrm{m} /$ Toman & 250 & EPrice & \\
$\mathrm{m} /$ Toman & 1250 & PPrice & Price \\
$\mathrm{M}^{2} /$ Toman & 1200 & SPrice & \\
$\mathrm{M}^{2} /$ Toman & 6000 & TPrice & \\
- & & & \\
$\mathrm{m}^{2}$ & & 1600 & Number of worker \\
\hline
\end{tabular}

improvement for future research. This skill level has been assigned based on the number of work units expected to be accomplished per time unit. For example, if a 3-member crew could finish each unit of assigned work in a 0.0067 time unit, then the skill level of each laborer will be approximately $50 \mathrm{~m} / \mathrm{h}$, calculated as: $((1 / 0.0067) / 3)=50 \mathrm{~m} / \mathrm{h}$;

6) A worker with a higher skill level could finish more work units in a time unit compared to a worker with a lower skill level. A meaningful difference has been assumed between workers and tasks by allocating a unique skill level to each kind of skill and allocating a quantitative value per task. Workers and task agents are different from each other. As there are behavioral and physical differences between workers and tasks in the real world, those kinds of differences are also available in the simulation model. Considering physical characteristics, workers are dynamic, while tasks are steady, as can be found in real world situations. In addition, workers are the subject but tasks are the object, and many physical differences have been considered between laborers and tasks. There are also substantial behavioral differences that can be found in state-charts (Figure 4);

7) The type of time for modeling has been considered continuous. The simulation method in the study is discrete. However, the simulation time is continuous. As a result, nothing has been mentioned in the article about the simulation method being continuous;

8) In the case study environment, the task agents are static, but the labor agents are dynamic and move around the environment;

9) The extent of the work accomplished during the simulation period has been calculated using the

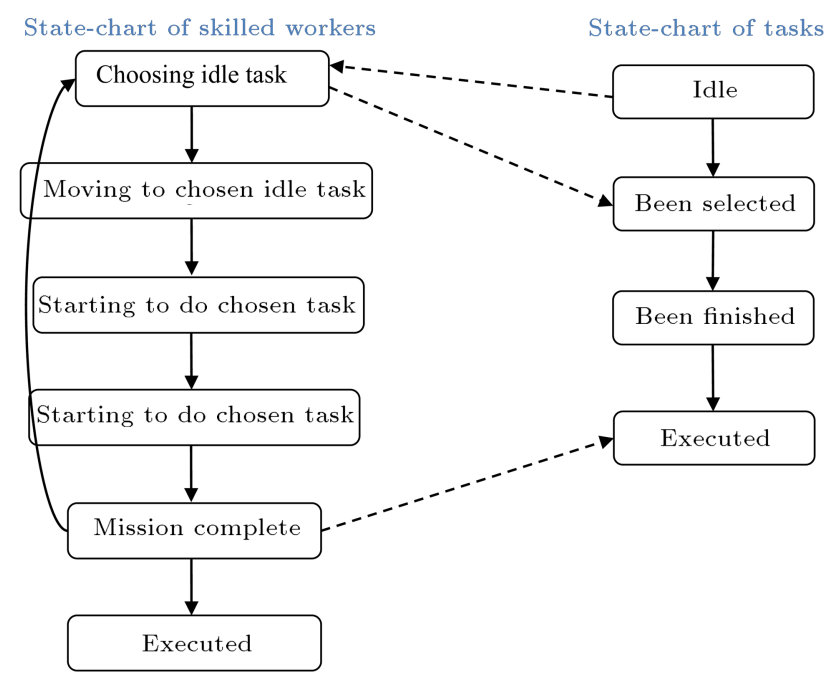

Figure 4. Agent's state-chart and their interaction. 
following productivity formula:

$$
\text { Work }=\text { Productivity } \times \text { Skill level. }
$$

10) The cost of each task is calculated using the following formula:

$$
\text { Cost }=\text { Work } \times \text { Value of price. }
$$

The model environment, where the agents' functions and their interactions have been defined, is based on the following rules:

1. A continuous environment has been chosen for agents;

2. The neighborhood of the agents has been defined based on the Euclidean neighborhood rule. The Euclidean neighborhood between agents is measured based on being connected by a straight line.

$$
\left(X-X_{0}\right)^{2}+\left(Y-Y_{0}\right)^{2}=r^{2} .
$$

Interaction among agents has been defined based on the following rules:

1. Labor productivity has been calculated using the following formula:

$$
\text { Pro }=1-C,
$$

where, $C$ is a constant value between 0 and 1 , indicating the magnitude of the effects that workflow effective factors have on labor productivity. As it gets closer to 1, labor efficiency reduces, and every task will have a delay in being finalized. In the current research, researchers have continuously attended the case study project and measured the real duration of performing every unit of activity to get the best value of $C$. The " $C$ " value has been calculated based on project data, the same as the skill level. However, the " $C$ " value validation is different from the skill level validation, as self model validation has been used in the research to validate the " $C$ " value. According to Table 2 , the best value of " $C$ ", based on several model runs, has been selected. Activities finished in 295 days, and, as can be seen from the multiple model runs, the closest outcome of simulation to base duration will happen at $C=0.4$. They have also compared the measured durations with a scheduled plan and extracted the value of $C=0.4$. It is important to mention that based on the study carried out in 2009 by Watkins et al. [35], the ideal value for constant " $C$ " in building construction projects is considered to be $C=0.4$ too (Table 2 );

2. Initially, the labor agent targets the task perfor-

\begin{tabular}{|c|c|c|c|c|c|c|}
\hline & \multicolumn{5}{|c|}{ "C $C$ " value } \\
\hline & & 0.1 & 0.2 & 0.3 & 0.4 & 0.5 \\
\hline \multirow{10}{*}{ 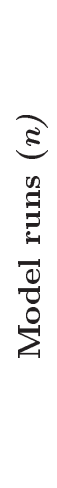 } & 1 & 71.93 & 127.84 & 235.7 & 288.61 & 350.6 \\
\hline & 2 & 78.2 & 143.61 & 248.68 & 286.71 & 357.12 \\
\hline & 3 & 74.52 & 142.42 & 268.79 & 293.15 & 365.42 \\
\hline & 4 & 74.1 & 153.36 & 238.66 & 299.78 & 367.43 \\
\hline & 5 & 74.02 & 135.52 & 238.74 & 300.15 & 352.91 \\
\hline & 6 & 75.99 & 124.74 & 243.31 & 299.24 & 339.49 \\
\hline & 7 & 74.23 & 139 & 237.45 & 282.29 & 340.63 \\
\hline & 8 & 75.08 & 141.37 & 239.77 & 291.39 & 342.13 \\
\hline & 9 & 74.59 & 126.77 & 231.72 & 301.73 & 366.82 \\
\hline & 10 & 75.22 & 133.11 & 250.58 & 299.84 & 340.54 \\
\hline
\end{tabular}
mance starting point, starts to move, and starts to work at the considered task;
Table 2. "C" value validation.

3. At every task's completion time, the labor agent searches the closest tasks on which no other labor agent is working, and begins to work on it;

4. The beginning, completion and interactions existing between the labor and the task agents will be set up by sending messages;

5. The labor agent characteristics used in the model are presented in Table 3;

6. Task agent characteristics used in the model are presented in Table 4;

7. The values of parameters used in the model are presented in Table 1.

\section{The model outputs}

The most important output of agent-based modeling is animating the system that is being analyzed. The purpose has been achieved by developing the model in AnyLogic software, where java coding has been used to import the model in the software. The model has been illustrated in Figure 5, in three steps: before run, after run, and when all tasks in the model have been completed. The cost change diagram for every working crew has been shown in Figure 6. The cost diagram of each of the labor crew will be changed by the variation in labor crew productivity, where it is a function of changes in the workflow.

Regarding the simulated cost output, effective factors on workflow have approximately raised labor costs by 16 percent. The simulation outputs have been validated by comparing them with the collected information from the case study. As shown in Table 5, the proposed model has estimated the labor cost of every labor crew with a smaller error percentage compared with planned estimation cost, indicating that the proposed model has a better performance in estimating labor costs. 
Table 3. labor agents' characteristics.

\begin{tabular}{|c|c|c|c|}
\hline Agent index & $\begin{array}{l}\text { Number of } \\
\text { existing } \\
\text { agents }\end{array}$ & Characteristic and color & \\
\hline TWorker & 3 & $\begin{array}{l}\text { Tillers as blue colored } \\
\text { dummies }\end{array}$ & \multirow{4}{*}{ Labor agent } \\
\hline PWorker & 3 & $\begin{array}{l}\text { Plumbers as yellow colored } \\
\text { dummies }\end{array}$ & \\
\hline SWorker & 3 & $\begin{array}{l}\text { Plasterers as green colored } \\
\text { dummies }\end{array}$ & \\
\hline EWorker & 3 & $\begin{array}{l}\text { Electricians as red colored } \\
\text { dummies }\end{array}$ & \\
\hline
\end{tabular}

Table 4. Tasks agent characteristics.

\begin{tabular}{|c|c|c|c|c|}
\hline Agent index & Unit & $\begin{array}{c}\text { Number of } \\
\text { existing agents }\end{array}$ & $\begin{array}{c}\text { Color and } \\
\text { characteristic }\end{array}$ & \\
\hline ETask & $\mathrm{m}$ & 15 & $\begin{array}{l}\text { Writing as red colored } \\
\text { rectangles }\end{array}$ & \\
\hline PTask & $\mathrm{m}$ & 51 & $\begin{array}{l}\text { Plumbing as yellow } \\
\text { colored rectangles }\end{array}$ & Tasks agent \\
\hline STask & $\mathrm{m}^{2}$ & 30 & $\begin{array}{l}\text { Plastering as green } \\
\text { colored rectangles }\end{array}$ & \\
\hline TTask & $\mathrm{m}^{2}$ & 36 & $\begin{array}{c}\text { Tiling as blue colored } \\
\text { rectangles }\end{array}$ & \\
\hline
\end{tabular}

Table 5. Comparison of model's error percentage and planning error percentage with reality.

\begin{tabular}{cccccc}
\hline $\begin{array}{c}\text { Planned error } \\
\text { to reality } \\
\text { (percent) }\end{array}$ & $\begin{array}{c}\text { Model error } \\
\text { to reality } \\
\text { (percent) }\end{array}$ & $\begin{array}{c}\text { Planned } \\
\text { cost } \\
\text { (Toman) }\end{array}$ & $\begin{array}{c}\text { Real } \\
\text { cost } \\
\text { (Toman) }\end{array}$ & $\begin{array}{c}\text { Simulated } \\
\text { cost } \\
\text { (Toman) }\end{array}$ & Subject \\
\hline $24 \%$ & $23 \%$ & 750,000 & 998,000 & 767,266 & Wiring \\
$28 \%$ & $15 \%$ & $1,100,000$ & $1,532,000$ & $1,291,419$ & Plumbing \\
$20 \%$ & $12 \%$ & 900,000 & $1,121,000$ & 975,750 & Plastering \\
$25 \%$ & $14 \%$ & $2,500,000$ & $3,345,000$ & $2,880,750$ & Tiling \\
\hline
\end{tabular}

As shown in Table 5, the proposed model has predicted the labor cost of every working crew with a smaller error percentage compared to planned estimation costs. It indicates that the proposed model has a better performance in estimating labor costs, as shown in Figure 7.

\section{Conclusion}

The results of the simulation confirm that the impact of effective factors on workflow can be predicted as an emergent property due to interaction between workers, their tasks and their environment (construction site). Agent-based modeling is applicable mostly in a discrete manner (jump from one event to another). It is a relatively new approach to simulate complex systems composed of interaction. Autonomous 'agents' that interact with each other and their underlying environment have been used to mimic a real-world scenario and replicate it.

Agent-based modeling and simulation include a computer simulation related to predicting system behavior in the future. The proposed method uses a bottom-up approach to predict labor costs in construction projects. AnyLogic is a powerful, and the only simulation tool that supports Discrete Event, Agent-Based, and System Dynamics Simulation. It has been developed not by simulation modelers but people 


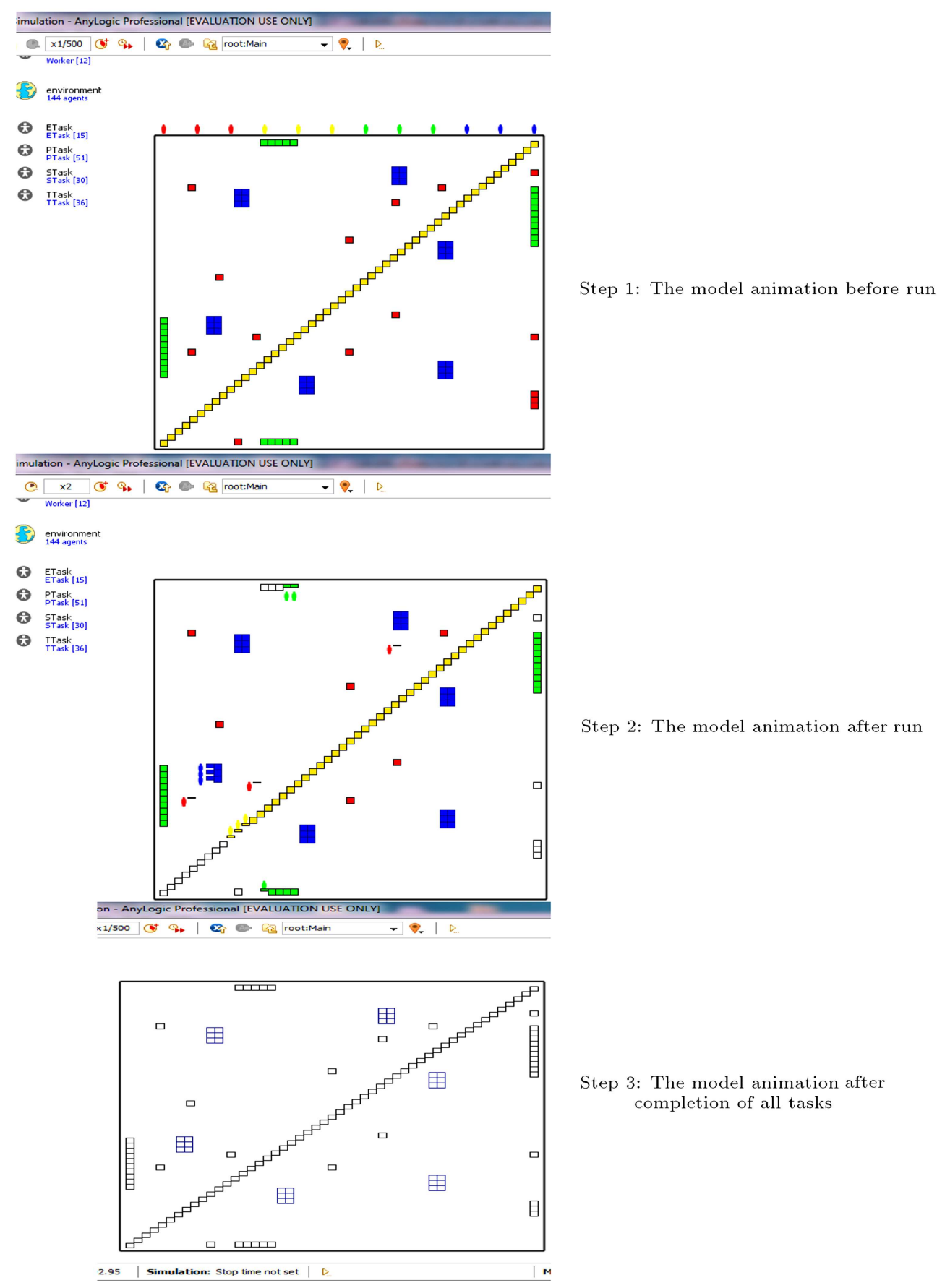

Figure 5. Steps of modeling animation.

with a background in distributed systems, concurrency theory and computer science. Therefore, none of the classical simulation modeling paradigms has been used as a foundation. Instead, approaches and languages designed to handle complexity in engineering software were implemented in the AnyLogic package [21]. We used a case study to serve as a tool for validating our model internal elements and the simulation results.

Labor cost prediction is an important element in construction projects. However, due to existing differences between real and ideal conditions in the planning period, accurate prediction of project parameters has been extremely difficult. Regarding the effective factors on construction labor efficiency, initial scheduling is not synchronized with the projects' real progress. In the current research, direct costs of the case study project have been produced by considering the productivity of 4 labor crews, and by simulation based on AnyLogic software. Considering the cost output, effective factors on workflow, including work interference, congestion, stacking of trades, concurrent operations, and inefficient crew size, have raised labor 


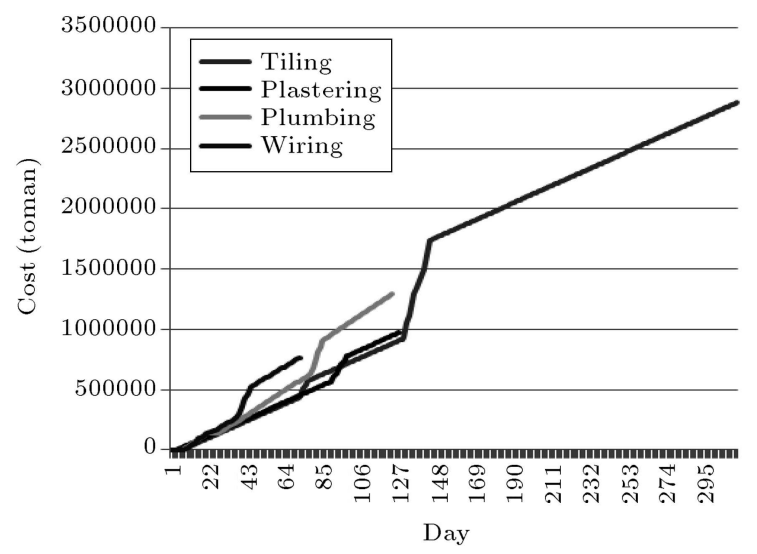

Figure 6. Cost output simulated based on time.

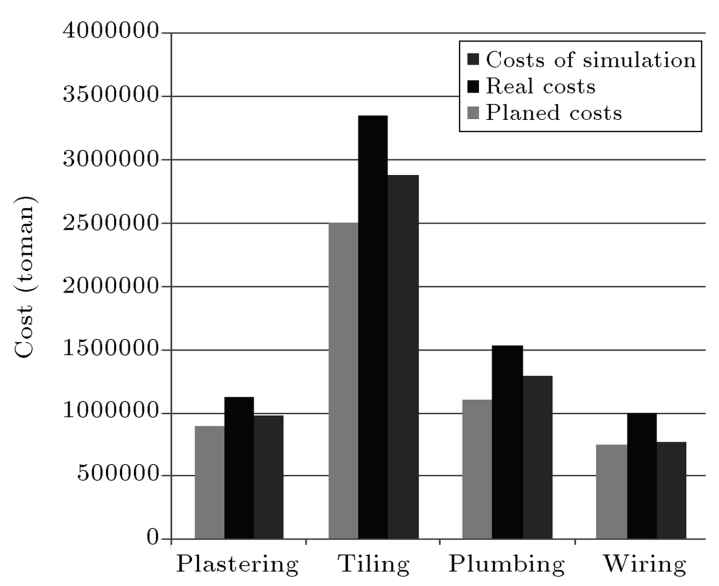

Figure 7. Comparison of real, simulated and planned costs.

costs by 16 percent, on average. The simulated outputs have been validated based on a comparison with information from case study projects. Also, the cost prediction presented by the model indicates the ratio of cost prediction presented by the model to planned cost prediction.

The complexity of the project in coding and using software significantly increased regarding the innovative approach used in the research. Effective factors on labor costs have been assumed as cumulative. So, one of the improvements to the current research can be consideration of each effective factor in a singular way. Researchers motivated by simulation are recommended to identify each of the effective factors separately. Labor cost predication will be more accurate, leading to better solutions for amending the contractors' related wasted costs, as total project costs are affected by these.

\section{References}

1. Enshassi, A., Mohamed, Sh., Abu Mustafa, Z. and Mayer, P.E. "Factors affecting labour productivity in building projects in the GHAZA strip", Journal of
Civil Engineering and Management, 13(4), pp. 245254 (2007).

2. Hanna, A.S., Chul-ki, Ch., Lackney, J.A. and Sullivan, K.T. "Impact of overmanning on mechanical and sheet metal labor productivity", Journal of Construction Engineering and Management, 133(1), pp. 22-28 (2007).

3. Jing, D. and El-Gafy, M. "Virtual organizational imitation for construction enterprises: Agent-based simulation framework for exploring human and organizational implications in construction management", Journal of Computing in Civil Engineering, 26(3), pp. 282-297 (2012).

4. Sawhney, A., Bashford, H., Walsh, K. and Mulky, A.R. "Agent-based modeling and simulation in construction", Proceeding of the Simulation Conference, pp. 1541-1547 (2003).

5. Teicholz, P. "A simulation approach to the selection of construction equipment", Technical Report No. 26, The Construction Institute, Stanford University (1963).

6. Jingsheng, Sh. and Abourizk, S. "Continuous and combined event-process models for simulating pipeline construction", Journal of Construction Management and Economics, 16(4), pp. 489-498 (1998).

7. Jingsheng, Sh. "Three methods for verifying and validating the simulation of a construction operation", Construction Management and Economics, 20(6), pp. 483-491 (2002).

8. Halpin, D.W. "An investigation of the use of simulation networks for modeling construction operations", Ph.D. Thesis presented to the University of Illinois, at Urbana-Champaign, Illinois, in partial fulfillment of the requirements for the degree of Doctor of Philosophy (1973).

9. Liuch, J.F. and Halpin, D.W. "Analysis of construction operations using microcomputers", Journal of the Construction Division, 108(1), pp. 129-145 (1981).

10. Paulson, B.C. "Interactive graphics for simulating construction operations", Journal of the Construction Division, ASCE, 104(1), pp. 69-76 (1987).

11. Touran, A. "Construction operations data acquisition and processing via time-lapse photography interfaced to a microcomputer", Ph.D. Dissertation, School of Civil Engineering, Stanford University, Stanford CA (1981).

12. Chang, D.Y. and Carr, R.I. "Resque: A resource oriented simulation system for multiple resource constrained processes", Proceedings of the PMI Seminar/Symposium, Milwaukee, Wisconsin, pp. 4-19 (1987).

13. Ioannou, P.G., Um-Cyclone User's Guide, Dept. of Civil Engineering, The University of Michigan, Ann Arbor (1989).

14. Zakeri, M., Olomolaiye, P.O., Holt, G.D. and Harris, F.C. "A survey of constraints on Iranian construction 
operatives' productivity", Construction Management and Economics, 14(5), pp. 417-426 (1996).

15. Hanna, A.S., Chang, Ch., Sullivan, K.T. and Lackney, J.A. "Impact of shift work on labor productivity for labor intensive contractor", Journal of Construction Engineering and Management, 134(3), pp. 197-204 (2008).

16. Soekiman, A., Soemardi, B.W. and Wirahadikusumah, R.D. "Factors relating to labor productivity affecting the project schedule performance in Indonesia", The Proceedings of the Twelfth East Asia-Pacific Conference on Structural Engineering and Construction (EASEC12), 14, pp. 865-873 (2011).

17. Rustom, R.N. and Yahia, A. "Estimating productivity using simulation: A case study of Gaza beach embankment protection project", Construction Innovation, $\mathbf{7}(2)$, pp. $167-186$ (2007).

18. Halpin, D.W., Micro Cyclone Area's Manual. Division of Construction Engineering and Management, Purdue University, West Lafayette, IN (1990).

19. Ingalls, R.G. "Introduction to simulation", In Proceeding of Simulation Conference, E. Yücesan, C.-H. Chen, J.L. Snowdon, and J.M. Charnes, Eds., pp. 7-16 (2002).

20. Shi, J. and AbouRizk, S.M. "Resource-based modeling for construction simulation", Journal of Construction Engineering and Management, 123(1), pp. 26-33 (1997).

21. Borshchev, A. and Filippov, A. "From system dynamics and discrete event to practical agent based modeling: Reasons, techniques, tools", International Conference of System Dynamics, XJ Technologies, www.XJtek.com and St. Petersburg Technical University (2004).

22. Macal, C.M. and North, M.J. "Tutorial on agent-based modeling and simulation", Journal of Simulation, 4(3), pp. 151-162 (2010).

23. Taylor, S., Agent-Based Modeling and Simulation, Palgrave Macmillan (2014).

24. Macal, C.M. and North, M.J. "Agent-based modeling and simulation", Proceedings of Simulation Conference, M.D. Rossetti, R.R. Hill, B. Johansson, A. Dunkin and R.G. Ingalls, Eds. (2009).

25. Bonabeau, E. "Agent-based modeling: Methods and techniques for simulating human system", In Proceedings of National Academy of Science, 99(3), pp. 72807287 (2002).

26. Theodore, T.A., Introduction to Discrete Event Simulation and Agent-Based Modeling, Springer-Verlag London Limited, ISBN-13: 978-0857291387, Edition: 2011th (2011).

27. Weisbuch, G., Complex Systems Dynamics: An Introduction to Automata Networks, (translated from
French by S. Ryckebusch), Addison-Wesley: Redwood City, CA (1991).

28. Kauffman, S.A., The Origins of Order: SelfOrganization and Selection in Evolution, Oxford University Press: Oxford, UK (1993).

29. Holland, J., Hidden Order: How Adaptation Builds Complexity, Addison-Wesley: Reading, MA (1995).

30. Langton, C.G. "Artificial life", The Proceedings of an Interdisciplinary Workshop on the Synthesis and Simulation of Living Systems, Held September 1987, Los Alamos, New Mexico, Vol. VI in Santa Fe Institute Studies in the Sciences of Complexity, Addison-Wesley: Reading, MA, pp. 1-47 (1989).

31. Macal, C.M. "Agent based modeling and artificial life", In: Meyers, R. (Ed.), Encyclopedia of Complexity and Systems Science, Springer: New York, pp. 112-131 (2009).

32. Howell, G. White Paper, Berkeley/Stanford CE\&M Research Workshop, Available online at: www.ce. berkeley.edu/ tommelein/CEMworkshop/Howe- 1l.pdf (1999).

33. Walsh, K., Sawhney, A. and Bashford, H. "Agentbased modeling and simulation in construction", Proceedings, Agent-Based Simulation 4, Montpellier, France (2003).

34. Chan, A., Scott, D. and Chan, A. "Factors affecting the success of a construction project", Journal of Construction Engineering and Management, 130(1), pp. 153-155 (2004).

35. Watkins, M., Mukherjee, A., Onder, N. and Mattila, K. "Using agent-based modeling to study construction labor productivity as an emergent property of individual and crew interactions", Journal of Construction Engineering and Management, 135(7), pp. 657-667 (2009).

36. Emrich, S., Serge S. and Florian, J., Fully Agent Based Modeling of Epidemic Spread Using Anylogic, Proc. EUROSIM (2007).

37. AnyLogic, XJ Technologies www.XJtek.com.

\section{Biographies}

Shahin Dabirian received his MS degree in Construction Engineering and Management from Iran University of Science and Technology, where he is currently a PhD degree student. He has published several papers in national and international Journals. His research interests include human resource management and simulation techniques.

Mostafa Khanzadi received his doctorate in Structural Engineering from the University of Hokkaido, Japan, and is currently Assistant Professor of Structural Engineering at Iran University of Science and Technology. He has published several papers in 
national and international Journals. His research interests include concrete technology and construction management.

Mehdi Moussazadeh received his MS degree in
Construction Engineering and Management from the Islamic Azad University, Science and Research Branch, Arak, Iran. He has written several papers related to agent-based modeling and simulation of labor productivity. 